\section{Revista de CIENCIAS AMBIENTALES Tropical Journal of Environmental Sciences}

Revista de Ciencias Ambientales (Trop J Environ Sci) e-ISSN: 2215-3896

(Julio-Diciembre, 2021) . Vol 55(2): 91-110

DOI: https://doi.org/10.15359/rca.55-2.5

Open Access: www.revistas.una.ac.cr/ambientales e-mail: revista.ambientales@una.ac.cr Guerrero-Morales J., Sampedro-Rosas L., Ruz-Vargas M., Silva-Gómez S., Carlos Fonseca C. y Gómez-Albores M.

\title{
Análisis multicriterio para el desarrollo urbano en zonas costeras en un contexto de cambio climático: Caso en Acapulco, México
}

\author{
Multicriteria analysis for urban development in coastal areas in a context of climate \\ change: Case in Acapulco, Mexico
}

\author{
Jesús Guerrero-Morales ${ }^{1}$, Laura Sampedro-Rosas ${ }^{2}$, Manuel Ignacio Ruz-Vargas ${ }^{3}$, \\ Sonia Emilia Silva Gómez ${ }^{4}$, Carlos Roberto Fonseca ${ }^{5}$, Miguel Ángel Gómez-Albores ${ }^{6}$
}

[Recibido: 24 de mayo 2020, Aceptado: 27 de enero 2021, Corregido: 14 de marzo 2021, Publicado: 1 de julio 2021]

\section{Resumen}

[Introducción]: El crecimiento urbano en zonas costeras de América Latina pone en riego a la población y contribuye al cambio climático. [Objetivos]: El objetivo de la presente investigación es generar una metodología que a futuro identifique la aptitud territorial para el desarrollo urbano en municipios costeros, considerando medidas de mitigación y adaptación al cambio climático, aspectos fisiográficos y político-administrativos. [Metodología]: Este estudio presenta el uso de sistemas de información geográfica (SIG) y la técnica del análisis de decisiones de criterios múltiples (MCDA, por sus siglas en inglés) para la selección de zonas idóneas para el desarrollo urbano en el municipio de Acapulco de Juárez, México. [Resultados]: Se crearon mapas temáticos del promedio de índices de vegetación, de la recarga potencial de agua subterránea, de tenencia de la tierra, de peligro de inundación, de restricciones de zonas urbanas existentes y de cuerpos de agua; posteriormente, se integraron en un MCDA para dotar de zonas urbanas aptas a futuro. En los resultados, se identificaron $367 \mathrm{~km}^{2}$ idóneos para el desarrollo urbano con menor impacto al ecosistema y a la vez, no son un riesgo para la población; asimismo, se identificaron zonas intermedias y no aptas que representan un peligro para la población y al ecosistema. [Conclusiones]: Este trabajo hace posible planear el territorio como una medida de mitigación y adaptación al cambio climático con el MCDA a través de SIG, en una zona afectada por los fenómenos hidrometeorológicos y una población en condiciones socioeconómicas adversas.

Palabras clave: Cambio climático; cambio de uso de suelo; evaluación multicriterio; inundación servicios ecosistémicos; tenencia de la tierra.

1 Candidato a doctor, Centro de Ciencias de Desarrollo Regional (CCDR), Universidad Autónoma de Guerrero (UAGRO), México; guerrero_m_jesus@outlook.com; https://orcid.org/0000-0001-5444-0632

2 Coordinadora, Centro de Ciencias de Desarrollo Regional (CCDR), Universidad Autónoma de Guerrero (UAGRO), México; laura_1953@live.com.mx; https://orcid.org/0000-0001-7966-8190

3 Profesor investigador, Facultad de Arquitectura y Urbanismo, Universidad Autónoma de Guerrero (UAGRO), México; maruz@uagro.mx; https://orcid.org/0000-0002-2698-316X

4 Profesora investigadora, posgrado en Ciencias Ambientales, Benemérita Universidad Autónoma de Puebla, México; soemsigo@gmail.com; https://orcid.org/0000-0002-6913-0386

5 Subdirector académico, Instituto Interamericano de Tecnología y Ciencias del Agua (IITCA), Universidad Autónoma del Estado de México (UAEMEX), México; crfonsecao@uaemex.mx; https://orcid.org/0000-0002-3377-6564

6 Coordinador de estudios avanzados, Instituto Interamericano de Tecnología y Ciencias del Agua (IITCA), Universidad Autónoma del Estado de México (UAEMEX), México; magomeza@uaemex.mx; https://orcid.org/0000-0002-6313-9187

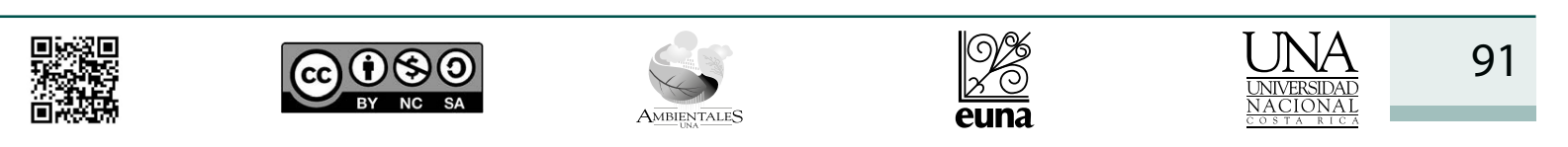




\section{Revista de CIENCIAS AMBIENTALES Tropical Journal of Environmental Sciences}

Revista de Ciencias Ambientales (Trop J Environ Sci) e-ISSN: 2215-3896

(Julio-Diciembre, 2021) . Vol 55(2): 91-110 DOI: https://doi.org/10.15359/rca.55-2.5

Open Access: www.revistas.una.ac.cr/ambientales e-mail: revista.ambientales@una.ac.cr Guerrero-Morales J., Sampedro-Rosas L., Ruz-Vargas M. Silva-Gómez S., Carlos Fonseca C. y Gómez-Albores M.

\begin{abstract}
[Introduction]: Urban growth in coastal areas of Latin America puts the population at risk and contributes to climate change. [Objective]: The investigation objective is to generate a methodology to identify territory aptitude for future urban development in coastal municipalities, considering mitigation measures and adaptation to climate change, physiographic and political-administrative aspects. [Methodology]: This study presents the use of geographic information systems (GIS) and the technique of multiple criteria decision analysis (MCDA) for the selection of suitable areas for urban development in Acapulco de Juárez, Mexico. [Results]: Thematic maps of average vegetation index, potential groundwater recharge, land tenure, flood hazard, actually urban areas and water bodies were created; later they were integrated into a MCDA to provide urban areas suitable for the future. The results identified $367 \mathrm{~km}^{2}$ suitable for urban development with less impact on the ecosystem and at the same time are not a risk to the population; Likewise, intermediate and unsuitable areas were identified that represent a danger to the population and the ecosystem. [Conclusions]: This work makes it possible to plan the territory as a mitigation and adaptation measure to climate change with the MCDA through GIS, in an area that has been distinguished by being affected by hydrometeorological phenomena and a population in adverse socioeconomic conditions.
\end{abstract}

Keywords: Climate change; ecosystem services; flood; land tenure; land use change; multi-criteria assessment.

\title{
1. Introducción
}

América Latina y el Caribe es la segunda región más urbanizada del planeta (United Nations, 2018). Algunos estudios aseguran que el uso de suelo urbano seguirá aumentando independientemente de la desaceleración del crecimiento poblacional (United Nations, 2018). Para generar estrategias de mitigación al crecimiento urbano,se deben considerar al menos cuatro aspectos: tenencia de la tierra, conservación de servicios ecosistémicos, condiciones fisiográficas y medidas de adaptación al cambio climático (Seghezzo et al., 2017; Llamas-Torres et al., 2019).

La tenencia de la tierra es un conjunto de reglas que definen el derecho de acceso a la tierra y el uso de sus recursos superficiales. Sarmiento et al., (2020) mencionan que en América Latina y el Caribe la tenencia de la tierra tiene el $53 \%$ de influencia en el cambio de uso de suelo y el riesgo. En ese sentido, el territorio en México se clasifica como: propiedad federal, propiedad social (comunal o ejido) y propiedad privada (Llamas-Torres et al., 2019). Uno de los problemas a los que se enfrenta la legislación en vínculo con el cambio de uso de suelo es que se contraponen los argumentos ecológicos y urbanos (ordenamiento ecológico y urbano) con atribuciones político administrativas (artículo 115 constitucional y la asamblea ejidal). Es decir, las leyes no son claramente vinculantes (Tiburcio-Robles et al., 2007).

En relación con los servicios ecosistémicos (SE), los ciclos de carbono e hidrológico son el principal soporte de los servicios de provisión y regulación que benefician tanto a la flora y fauna como al ser humano Viglizzo et al., (2011). Las funciones de los ciclos previamente citados, como el de purificar el aire, filtrar y almacenar el agua en el subsuelo, son obstruidas por la expansión de las ciudades. En ese sentido, Viglizzo et al., (2011) mencionan que donde no hay carbono orgánico ni agua no hay servicios ecosistémicos ni vida.

En zonas costeras, el crecimiento urbano para infraestructura turística y el incremento del nivel del mar por cambio climático generan un riesgo latente (IPCC, 2014). Es necesario integrar

\begin{tabular}{|c|c|c|c|c|c|}
\hline 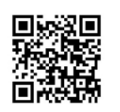 & (c) (1) & $\overbrace{\text { AMBERTALIES }}$ & $\frac{1 \%}{\text { euna }}$ & 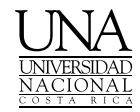 & 92 \\
\hline
\end{tabular}




\section{Revista de CIENCIAS AMBIENTALES Tropical Journal of Environmental Sciences}

Revista de Ciencias Ambientales (Trop J Environ Sci) e-ISSN: 2215-3896

(Julio-Diciembre, 2021) . Vol 55(2): 91-110 DOI: https://doi.org/10.15359/rca.55-2.5

Open Access: www.revistas.una.ac.cr/ambientales e-mail: revista.ambientales@una.ac.cr Guerrero-Morales J., Sampedro-Rosas L., Ruz-Vargas M., Silva-Gómez S., Carlos Fonseca C. y Gómez-Albores M.

medidas de adaptación y mitigación al cambio climático (CC) acompañando de políticas territoriales que favorezcan a una planeación urbana idónea, que reduzca los daños ambientales del cambio de uso de suelo, y a su vez disminuya los riesgos que genera el calentamiento global, como lo recomienda el quinto informe del Panel Intergubernamental de Cambio Climático (IPCC, 2014).

Estas acciones deben ser prioritarias en países en vías de desarrollo y subdesarrollados donde las economías no están consolidadas, como sucede en América Latina, y los desastres naturales se convierten en emergencias nacionales.

El análisis de decisión de criterios múltiples (MCDA, por sus siglas en inglés) es una técnica de soporte en la toma de decisiones enfocada a resolver un problema donde intervienen distintos criterios, conocidos como factores y restricciones, para elegir la solución óptima (Riccioli et al., 2016). Esta herramienta se ha desarrollado en Sistemas de Información Geográfica (SIG) para analizar el territorio y apoyar en la elección de zonas aptas para distintos fines.

Se han realizado investigaciones con MCDA a través de SIG para la ubicación de rellenos sanitarios, riesgo de inundación, conservación de servicios ecosistémicos y para el crecimiento urbano (Eastman, 2016; Riccioli et al., 2016; Llamas-Torres et al., 2019; Tiwari et al., 2019). Además, Seghezzo et al. (2017) utiliza MCDA involucrando tenencia de la tierra en países de América Latina.

De los trabajos antes mencionados, en algunos casos se indican zonas de conservación a futuro, pero no se toma en cuenta la propiedad de la tierra o los servicios ecosistémicos no son incorporados (Seghezzo et al., 2017). Además, las ciudades costeras presentan un factor adicional que debe ser considerado, el peligro de inundación por aumento del nivel del mar debido al CC. Este aspecto deber ser de especial interés a los países colindantes con el Océano Pacífico por el fenómeno del Niño.

El objetivo de esta investigación es aplicar el método de análisis de decisiones multicriterio a través de SIG para la planificación de zonas idóneas para el desarrollo urbano como una medida de mitigación y adaptación al CC en el municipio de Acapulco de Juárez.

Para desarrollar esta metodología se crearon factores y restricciones (mapas temáticos) como entrada al MCDA. Al resultado del análisis multicriterio se le realizó una estratificación por nivel de idoneidad para el crecimiento urbano.

En el presente trabajo se realizó una caracterización general de la zona de estudio, resaltando las condiciones fisiográficas y las principales características socioeconómicas que se han relacionado con el cambio de uso de suelo. En la metodología se hace una breve descripción de la elaboración de cada uno de los mapas temáticos y se describe la fórmula del MCDA. En resultados y conclusiones se muestran las zonas con menor impacto al ecosistema y a la vez no representa un riesgo para la población por inundación y se da prioridad a las zonas con mayor intervención humana, a esto se le denomina áreas idóneas para el desarrollo urbano.

\begin{tabular}{|c|c|c|c|c|c|}
\hline 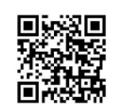 & (c) () & $\underset{\text { AMBIENTALS }}{\leftrightarrow}$ & $\frac{1 \%}{2 \%}$ & 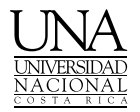 & 93 \\
\hline
\end{tabular}




\section{Revista de CIENCIAS AMBIENTALES Tropical Journal of Environmental Sciences}

Revista de Ciencias Ambientales (Trop J Environ Sci) e-ISSN: 2215-3896

(Julio-Diciembre, 2021) . Vol 55(2): 91-110 DOI: https://doi.org/10.15359/rca.55-2.5

Open Access: www.revistas.una.ac.cr/ambientales e-mail: revista.ambientales@una.ac.cr Guerrero-Morales J., Sampedro-Rosas L., Ruz-Vargas M. Silva-Gómez S., Carlos Fonseca C. y Gómez-Albores M.

\section{Marco teórico}

Los servicios ecosistémicos (SE) son un modelo conceptual que se define como: los componentes y procesos de los ecosistemas que son consumidos, disfrutados o que conducen a aumentar el bienestar humano tomando en cuenta la demanda de los beneficiarios, así como la dinámica de los ecosistemas (MEA, 2005; Vigglizo et al., 2011). Las Naciones Unidas a través de la iniciativa Evaluación de los Ecosistemas del Milenio MEA (2005) clasifican los SE en: de provisión, regulación, servicios culturales y de soporte. Los SE de soporte son los encargados del funcionamiento de los demás servicios. Por tal motivo el ciclo hidrológico y de carbono son considerados en esta investigación como SE de soporte.

La necesidad de desarrollar investigación en relación con los SE para la preservación de los ecosistemas en América Latina cobra una importancia preponderante debido a la diversidad biológica y cultural que interactúan, y se complejizan ante la economía global (Sarmiento et al., 2020; Viglizzo et al., 2011).

$\mathrm{Al}$ respecto, los sistemas de información geográfica son herramientas que han servido para identificar variables en un espacio geográfico que tiene intereses de conservación y de explotación. En ese orden de ideas, las ciencias ambientales permiten el surgimiento de un paradigma emergente de conciliación entre los aspectos ecosistémicos y socioeconómicos.

\section{Metodología}

\subsection{Zona de estudio}

La presente investigación se desarrolló en Acapulco de Juárez, uno de los 81 municipios del Estado de Guerrero, cuarto lugar a nivel nacional en biodiversidad (Botello et al., 2015). La superficie territorial del municipio de Acapulco es de $1727 \mathrm{~km}^{2}$. Se ubica en el centro-sur de México en colindancia con el Océano Pacífico. Una de las características de esta región es la accidentada orografía que va desde los 0 hasta los $2079 \mathrm{msnm}$ (UAF, 2008). Presenta una temperatura mínima de $22^{\circ} \mathrm{C}$ y una máxima de $28^{\circ} \mathrm{C}$. La precipitación se concentra en verano y va de los 2 a $15 \mathrm{~mm}$, el clima predominante es cálido subhúmedo (clasificación de Köppen; Retama et al., 2019). Las condiciones climáticas favorecen una variedad florística y faunística importante (Botello et al., 2015; Retama et al., 2019). Los principales cuerpos de agua son: Laguna de Tres Palos, río Papagayo y río La Sabana. El municipio cuenta con dos zonas de conservación (Figura 1): Isla de la Roqueta y el área natural protegida parque nacional El Veladero (CONANP, 2018; INEGI, 2020).

\begin{tabular}{|c|c|c|}
\hline 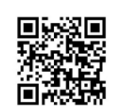 & (c) (i) (\$) & 94 \\
\hline
\end{tabular}




\section{Revista de CIENCIAS AMBIENTALES Tropical Journal of Environmental Sciences}

Revista de Ciencias Ambientales (Trop J Environ Sci) e-ISSN: 2215-3896

(Julio-Diciembre, 2021) . Vol 55(2): 91-110 DOI: https://doi.org/10.15359/rca.55-2.5

Open Access: www.revistas.una.ac.cr/ambientales e-mail: revista.ambientales@una.ac.cr Guerrero-Morales J., Sampedro-Rosas L., Ruz-Vargas M., Silva-Gómez S., Carlos Fonseca C. y Gómez-Albores M.

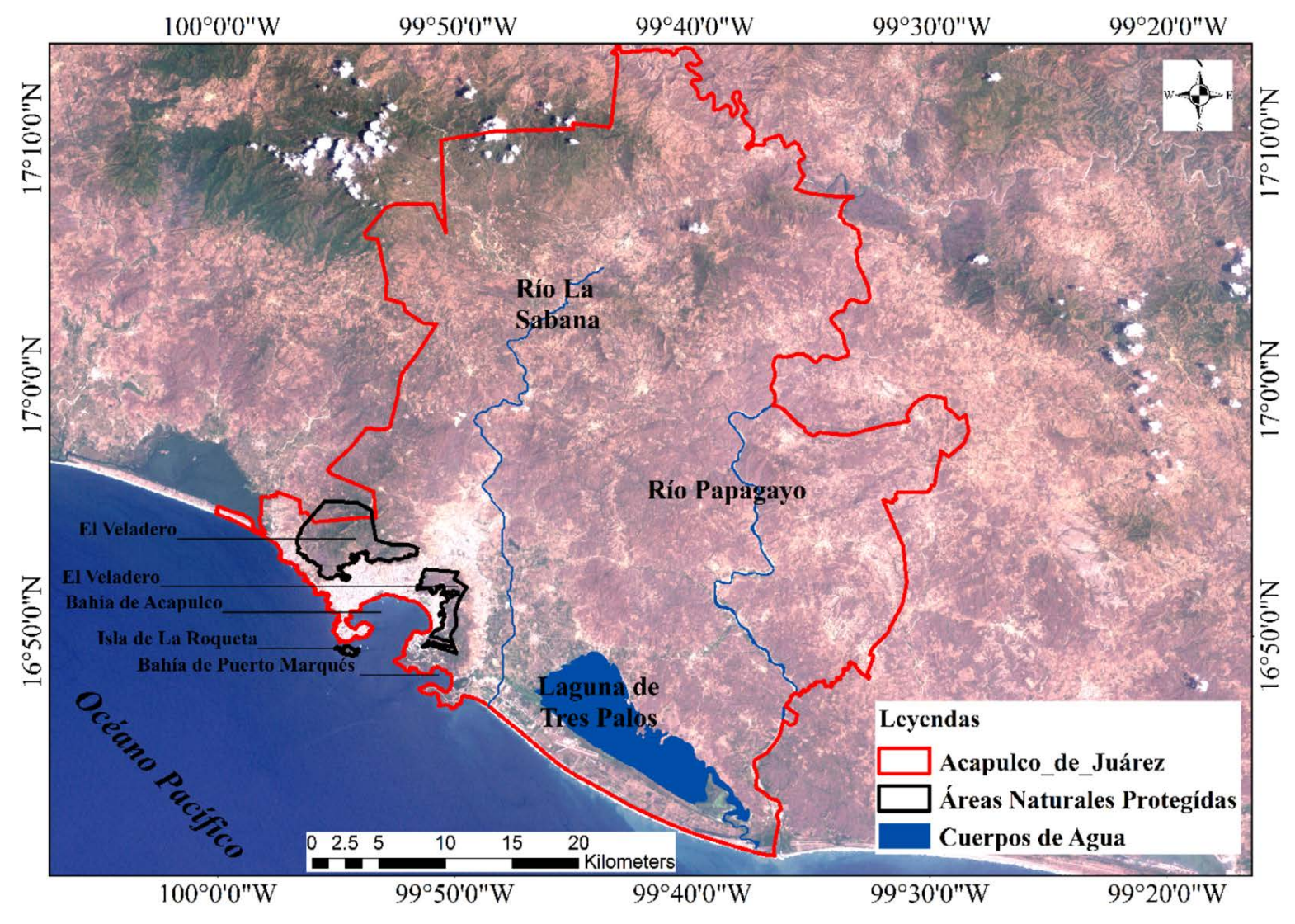

Figura 1. Localización de Acapulco de Juárez, Guerrero, México.

Figure 1. Location of Acapulco de Juárez, Guerrero, México.

La proximidad al Ecuador y la línea litoral hacen de Acapulco un sitio vulnerable a fenómenos hidrometeorológicos. Los últimos ciclones tropicales: Paulina en 1997, Henrriet en 2007 y Manuel en 2013 cobraron cientos de vidas y pérdidas económicas considerables (Rodríguez, 2017).

En términos socioeconómicos, en 1950 Acapulco inició su camino para convertirse en el destino turístico más popular de Latinoamérica. En los años subsecuentes se desarrollaron construcciones con fines turísticas de mayor volumen, para que su economía se centre en el sector servicios. A partir de esa década el turismo vendrá funcionado como rector urbano desigual en Acapulco. La demanda turística y las exigencias del mercado internacional obligaron a las élites políticas y económicas a radicalizar y ampliar sus prácticas extractivistas, no solo con los recursos naturales y territoriales, sino también con lo humano.

De 2000 a 2010, el índice de marginación "alto y muy alto" permaneció constante con el 60 \% del total de la población (Consejo Nacional de Población, 2010). Hoy, el 83 \% de la población económicamente activa se concentra en el sector turístico. De esta, el $50 \%$ apenas gana para cubrir sus necesidades básicas. La agricultura y la industria son incipientes en la región (INEGI, 2015).

\begin{tabular}{|c|c|c|}
\hline 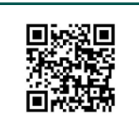 & (c) (i) () () () & 95 \\
\hline
\end{tabular}




\section{Revista de CIENCIAS AMBIENTALES Tropical Journal of Environmental Sciences}

Revista de Ciencias Ambientales (Trop J Environ Sci) e-ISSN: 2215-3896

(Julio-Diciembre, 2021) . Vol 55(2): 91-110 DOI: https://doi.org/10.15359/rca.55-2.5 Open Access: www.revistas.una.ac.cr/ambientales e-mail: revista.ambientales@una.ac.cr Guerrero-Morales J., Sampedro-Rosas L., Ruz-Vargas M. Silva-Gómez S., Carlos Fonseca C. y Gómez-Albores M.

\subsection{Metodología}

Inicialmente, para desarrollar el MCDA fue necesario crear factores $(F)$ y restricciones $(R)$. Los primeros sustentan la idoneidad para el desarrollo urbano y están representados por los mapas temáticos siguientes: potencial de recarga de agua subterránea (PGR), promedio de índices de vegetación (IV), tenencia de la tierra, pendientes del terreno, registros oficiales de inundaciones y de zonas potenciales de inundación por aumento del nivel del mar debido al CC. Las $\mathrm{R}$, expresan la nula idoneidad para el desarrollo urbano en zonas urbanas existentes y cuerpos de agua, para lo cual fue necesario elaborar mapas de esas áreas. Posteriormente, se efectuó la integración y los mapas temáticos F y R con el MCDA para generar un mapa de idoneidad para el desarrollo urbano (Tiwari et al., 2018). El material espacial empleado y sus especificaciones para crear los mapas temáticos se observan en el Cuadro 1.

Cuadro 1. Material cartográfico para la obtención de mapas temáticos.

Table 1. Cartographic material to obtain thematic maps.

\begin{tabular}{|c|c|c|c|c|c|}
\hline Material cartográfico & Formato & Resolución/escala & Año & Mapa temático & Fuente \\
\hline Áreas geoestadísticas básicas & Vector & $1: 250000$ & 2019 & Tenencia de la tierra & (INEGI, 2020) \\
\hline Registro agrario nacional & Vector & $1: 250000$ & 2019 & Tenencia de la tierra & $(\mathrm{RAN}, 2018)$ \\
\hline Áreas naturales protegidas & Vector & $1: 250000$ & 2018 & Tenencia de la tierra & (CONANP, 2018) \\
\hline Precipitación & Raster & $1 \mathrm{~km}$ & 2000 & PGR & (WorldClim, 2018) \\
\hline Temperatura & Raster & $1 \mathrm{~km}$ & 2000 & PGR & (WorldClim, 2018) \\
\hline Tipo de suelo & Vector & $1: 250000$ & 2007 & PGR & (INEGI, 2020) \\
\hline $\begin{array}{l}\text { Modelo digital de elevación } \\
\text { (MDE) }\end{array}$ & Raster & $12.5 \mathrm{~m}$ & 2011 & $\begin{array}{l}\text { PGR, pendientes, nivel } \\
\text { del mar }\end{array}$ & (UAF, 2008) \\
\hline Imágenes Landsat 5 & Raster & $30 \mathrm{~m}$ & 1986 & IV & (USGS, 2019) \\
\hline Imágenes Landsat 5 & Raster & $30 \mathrm{~m}$ & 1987 & IV & (USGS, 2019) \\
\hline Imágenes Landsat 7 & Raster & $30 \mathrm{~m}$ & 2001 & IV & (USGS, 2019) \\
\hline Imágenes Landsat 7 & Raster & $30 \mathrm{~m}$ & 2003 & IV & (USGS, 2019) \\
\hline Imágenes Landsat 8 & Raster & $30 \mathrm{~m}$ & 2017 & $\begin{array}{l}\text { IV y restricción de } \\
\text { zonas urbanas }\end{array}$ & (USGS, 2019) \\
\hline Imágenes Landsat 8 & Raster & $30 \mathrm{~m}$ & 2017 & IV & (USGS, 2019) \\
\hline Altas de Peligros Naturales & Vector & $1: 250000$ & 2005 & $\begin{array}{l}\text { Inundación por } \\
\text { registros oficiales }\end{array}$ & (SEDESOL 2004) \\
\hline $\begin{array}{l}\text { Inundación por el huracán } \\
\text { Ingrid y Manuel }\end{array}$ & Raster & $1: 250000$ & 2013 & $\begin{array}{l}\text { Inundación por } \\
\text { registros oficiales }\end{array}$ & $(\mathrm{PC}, 2020)$ \\
\hline Cuerpos de agua & Raster & $1: 250000$ & 2017 & $\begin{array}{l}\text { Cuerpos de agua y nivel } \\
\text { del mar }\end{array}$ & (INEGI, 2020) \\
\hline
\end{tabular}

Las herramientas y algoritmos empleados fueron: unión de vectores, balance hidrológico, cálculo de índices de vegetación (IV) y promedio de estos, estimación de pendientes de terreno, clasificación supervisada, buffer, rio principal, probabilidad de inundación por aumento del nivel del mar debido al CC, operacionalización de F y R, y por último se realizó el MCDA. En

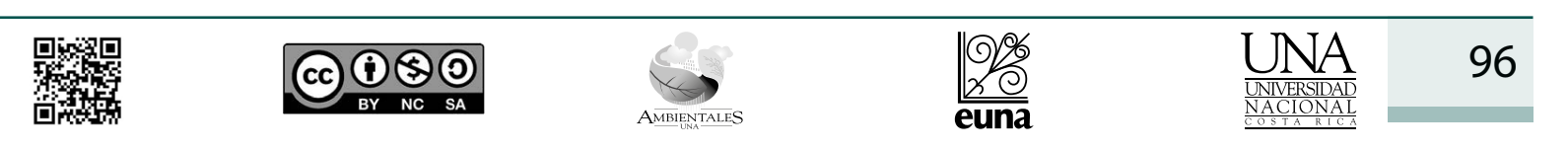




\section{Revista de CIENCIAS AMBIENTALES Tropical Journal of Environmental Sciences}

Revista de Ciencias Ambientales (Trop J Environ Sci) e-ISSN: 2215-3896

(Julio-Diciembre, 2021) . Vol 55(2): 91-110 DOI: https://doi.org/10.15359/rca.55-2.5 Open Access: www.revistas.una.ac.cr/ambientales e-mail: revista.ambientales@una.ac.cr Guerrero-Morales J., Sampedro-Rosas L., Ruz-Vargas M., Silva-Gómez S., Carlos Fonseca C. y Gómez-Albores M.

la (Figura 2) se observa el material cartográfico de entrada, los procesos realizados y los mapas temáticos de salida. Todo el análisis espacial se realizó con el software TerrSet (Eastman, 2016). A continuación, se describen algunas características de elaboración de mapas temáticos.

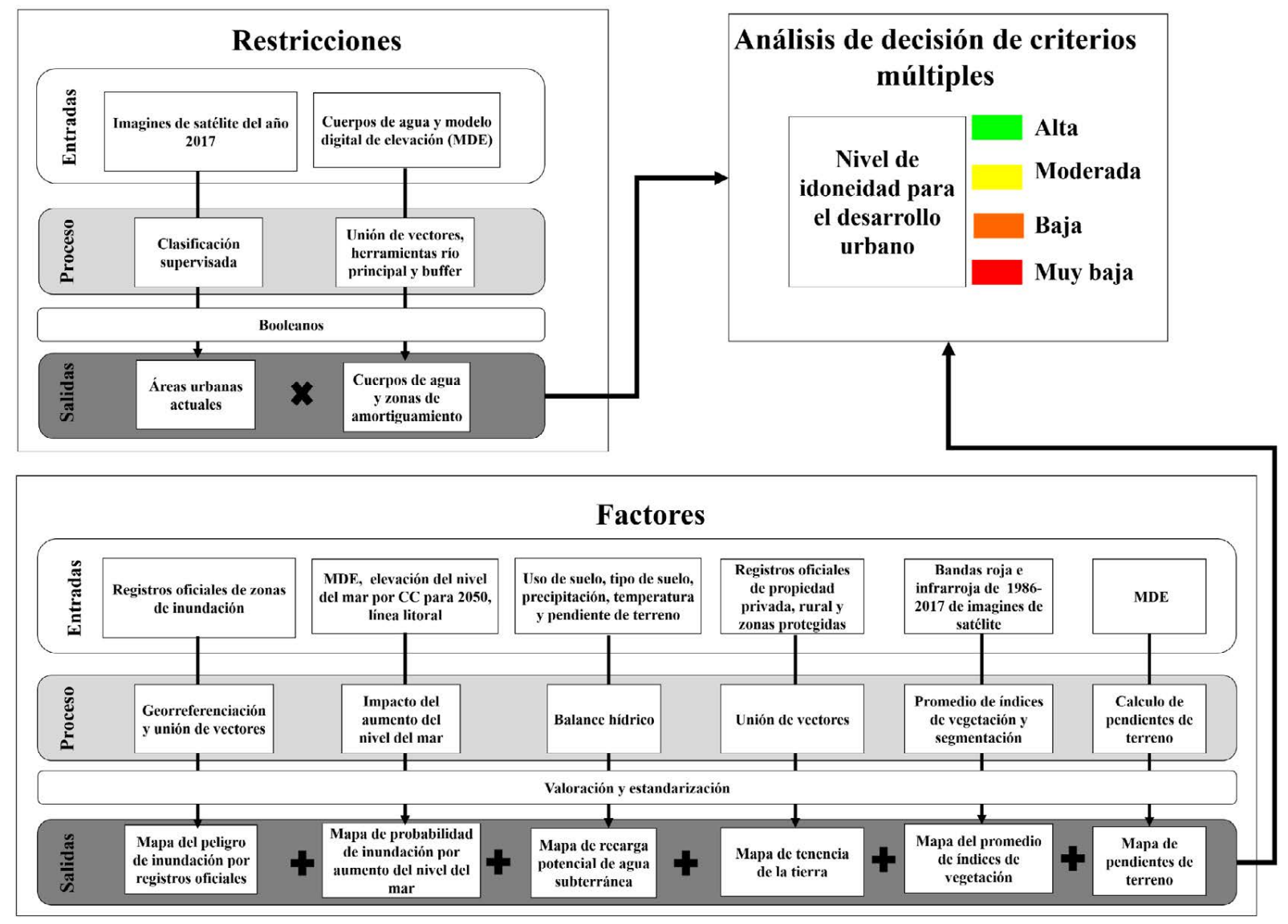

Figura 2. Esquema metodológico, Factores, restricciones y MCDA.

Figure 2. Methodological scheme, factors, restrictions and MCDA.

\subsection{Factores (F)}

\subsubsection{Mapa de tenencia de la tierra}

Se unieron los archivos vectoriales del Registro Agrario Nacional (RAN, 2018), las Áreas Geoestadísticas Básicas (INEGI, 2020) y Áreas Naturales Protegidas (CONANP, 2018). A la propiedad privada o AGEB se asignó el menor valor de 0.1 (por tanto, más apto para el desarrollo urbano). En los RAN, a los caseríos rurales se les asigno 0.2 debido a que están destinados para

\begin{tabular}{|c|c|c|}
\hline 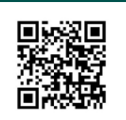 & (c) (i) () () & 97 \\
\hline
\end{tabular}




\section{Revista de CIENCIAS AMBIENTALES Tropical Journal of Environmental Sciences}

Revista de Ciencias Ambientales (Trop J Environ Sci) e-ISSN: 2215-3896

(Julio-Diciembre, 2021) . Vol 55(2): 91-110 DOI: https://doi.org/10.15359/rca.55-2.5 Open Access: www.revistas.una.ac.cr/ambientales e-mail: revista.ambientales@una.ac.cr Guerrero-Morales J., Sampedro-Rosas L., Ruz-Vargas M., Silva-Gómez S., Carlos Fonseca C. y Gómez-Albores M.

asentamientos agrarios; a las parcelas individuales se les asigno 0.4 debido a que su permanecía o cambio de uso de suelo afectaría o beneficiaría en lo individual dentro del ejido; 0.6 se asignó a la propiedad comunal debido a que el cambio de uso de suelo dependerá del número de personas involucradas. Las ANP y zonas sin registro aparente se asignaron el valor de 0.8, por la necesidad de preservar áreas con baja intervención humana.

\subsubsection{Mapa del potencial de recarga de agua subterránea (PGR) 2017}

El PGR es estimado con el modelo distribuido de Fonseca et al. (2017) a partir de la precipitación (WorldClim, 2018), el escurrimiento potencial que depende de la pendiente (UAF, 2008), el tipo de suelo (INEGI, 2020) y el uso de suelo; y la evapotranspiración, que se calculó por el método de Thornthwaite con base en temperaturas (WorldClim, 2018). El PGR fue normalizado con la función monotónica incremental de 0 a 1.

\subsubsection{Mapa del promedio de índices de vegetación 1986-2017}

Se obtuvieron las bandas rojas e infrarrojas de los satélites Landsat de los meses más secos y los meses más húmedos de 1986-2017 (Huete et al., 2015; USGS, 2019). Con estas bandas se generaron índices de vegetación de corrección transformada (CTVI) y se realizó un promedio (Riccioli et al., 2016; Tiwari et al., 2019). La imagen obtenida fue normalizada con la función monotónica incremental de 0 a 1.

\subsubsection{Mapa de pendientes del terreno}

Se realizó una capa que exprese las pendientes aptas para el crecimiento urbano con el DEM (UAF, 2008). Con pendientes de $2-11.9 \%$ se asignó un valor de 0.1 ; de $12-21.9 \%$ un valor de 0.2 , 22-31.9 \% un valor de 0.4 ; de 32-41.9 \% un valor de 0.6 ; de $42-51.9 \%$ un valor de 0.8 y de $52 \%$ en adelante y de 0-1.9 \% se asignó un valor de 1.0 (Tiwari et al., 2019).

\subsubsection{Zonas de inundación de registros oficiales}

Se obtuvieron las zonas de riesgo de inundación (SEDESOL, 2004) y las zonas afectadas por el huracán Ingrid y Manuel en 2013 (Protección Civil, 2020) de documentos oficiales. Esta información fue integrada y operacionalizada de la siguiente forma 1.0, 0.8, 0.6 y 0.1 que corresponde a riesgo alto, medio, bajo y sin riesgo, respectivamente.

\subsubsection{Mapa de peligro de inundación por aumento del nivel del mar por cambio CC}

Para generar un mapa de probabilidad de inundación se toma como límite central el nivel del mar pronosticado de acuerdo a un escenario de emisiones de CC (RCP por sus siglas en ingles) y se asignan valores continuos de 0 a 1 , siguiendo una distribución normal tomando como

\begin{tabular}{|c|c|c|c|c|c|}
\hline 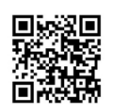 & (c) () & $\overbrace{\text { AMBENEMIIISS }}$ & $\frac{1 \%}{2 \%}$ & 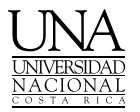 & 98 \\
\hline
\end{tabular}




\section{Revista de CIENCIAS AMBIENTALES Tropical Journal of Environmental Sciences}

Revista de Ciencias Ambientales (Trop J Environ Sci) e-ISSN: 2215-3896

(Julio-Diciembre, 2021) . Vol 55(2): 91-110 DOI: https://doi.org/10.15359/rca.55-2.5

Open Access: www.revistas.una.ac.cr/ambientales e-mail: revista.ambientales@una.ac.cr Guerrero-Morales J., Sampedro-Rosas L., Ruz-Vargas M. Silva-Gómez S., Carlos Fonseca C. y Gómez-Albores M.

parámetro una desviación estándar definida por el RCP seleccionado. Los valores de probabilidad antes mencionados son estimados a partir de un modelo digital de elevación (DEM).

Se seleccionó el escenario de CC RCP 8.5 con aumento del nivel del mar de $0.3 \mathrm{~m}$, con una desviación estándar 0.08 para el año 2050 (IPCC, 2014); el DEM (UAF, 2008) y la línea litoral del municipio (INEGI, 2020). A partir de esta información se utilizó el modelador de adaptación al cambio climático del software TerrSet. Los factores y su valoración se observan en el (Cuadro 2).

Cuadro 2. Factores y valor de idoneidad para el desarrollo urbano.

Table 2. Factors and suitability value for urban development.

\begin{tabular}{|c|c|c|c|c|c|c|c|}
\hline $\begin{array}{l}\text { Inundación por } \\
\text { aumento del nivel } \\
\text { del mar }\end{array}$ & 0.0 & Continuo & Continuo & Continuo & Continuo & 1.0 & Ninguno \\
\hline PGR & 0.0 & Continuo & Continuo & Continuo & Continuo & 1.0 & Estandarización \\
\hline Promedio de CTVI & 0.0 & Continuo & Continuo & Continuo & Continuo & 1.0 & Estandarización \\
\hline \multirow{3}{*}{$\begin{array}{l}\text { Inundación de } \\
\text { registros oficiales }\end{array}$} & 0.1 & 0.1 & 0.1 & 0.6 & 0.8 & 1.0 & Operacionalización \\
\hline & Sin riesgo & Sin riesgo & Sin riesgo & Riesgo bajo & $\begin{array}{l}\text { Riesgo } \\
\text { moderado }\end{array}$ & Alto riesgo & \\
\hline & 0.1 & 0.2 & 0.4 & 0.6 & 0.8 & 1.0 & Operacionalización \\
\hline \multirow[t]{2}{*}{ Tenencia de la tierra } & Privada (AGEB) & $\begin{array}{l}\text { Asentamiento } \\
\text { del ejido }\end{array}$ & $\begin{array}{l}\text { Parcela del } \\
\text { ejido }\end{array}$ & $\begin{array}{l}\text { Comunal } \\
\text { en el ejido }\end{array}$ & $\begin{array}{l}\text { Zona } \\
\text { federal }\end{array}$ & Cuerpos de agua & \\
\hline & 0.1 & 0.2 & 0.4 & 0.6 & 0.8 & 1.0 & Agrupación \\
\hline Pendiente de terreno & $2-11.99 \%$ & $12-21.99 \%$ & $22-31.99 \%$ & $32-41.99 \%$ & $42-51.99 \%$ & $\begin{array}{l}52 \%< \\
0-1.999 \%\end{array}$ & \\
\hline Idoneidad & Alta & Moderada & & Baja & & Muy baja & Tipo de valoración \\
\hline
\end{tabular}

\subsection{Restricciones $(\mathrm{R})$}

\subsubsection{Zonas urbanas existentes}

Se obtuvieron las zonas urbanas del 2017 de Acapulco a partir de una clasificación supervisada con imágenes Landsat 8. De esta información se creó un mapa booleano.

\subsubsection{Cuerpos de agua}

Se obtuvieron los cuerpos de agua permanentes de INEGI (2020). El río intermitente de mayor caudal se delimitó con el DEM (UAF, 2008) y la herramienta Runoff (Eastman, 2016). Posteriormente, a los cuerpos de agua antes mencionados se aplicó un buffer de $20 \mathrm{~m}$ para la preservación ecológica y disminuir el peligro de inundación de asentamientos. A la línea litoral se asigna un buffer de 100 m (Hawes y Smith, 2005). De esta información se creó un mapa booleano.

\begin{tabular}{|c|c|c|c|c|}
\hline 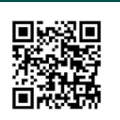 & (c) (i) (\$) & $\underset{\text { AMBIENTALIS }}{S}$ & $\frac{1 \%}{\frac{\%}{2}}$ & 99 \\
\hline
\end{tabular}




\section{Revista de CIENCIAS AMBIENTALES Tropical Journal of Environmental Sciences}

Revista de Ciencias Ambientales (Trop J Environ Sci) e-ISSN: 2215-3896

(Julio-Diciembre, 2021) . Vol 55(2): 91-110 DOI: https://doi.org/10.15359/rca.55-2.5 Open Access: www.revistas.una.ac.cr/ambientales e-mail: revista.ambientales@una.ac.cr Guerrero-Morales J., Sampedro-Rosas L., Ruz-Vargas M. Silva-Gómez S., Carlos Fonseca C. y Gómez-Albores M.

\subsection{Análisis de evaluación multicriterio}

Las áreas idóneas para el desarrollo urbano son seleccionadas por medio del análisis de decisiones de criterios múltiples (MCDA por sus siglas en inglés; Seghezzo et al., (2017). Los factores $F$ se suman de $j$ a $n$ que proporcionan las zonas más adecuadas para el desarrollo urbano. Las restricciones $R$ de $j$ a $n$ son multiplicadas para eliminar zonas imposibles de urbanizar (ver Ecuación 1), $x$ en la ecuación es 1 debido a que todos los factores tienen el mismo peso de importancia.

$$
R T U=\sum_{i=1}^{n} x_{i} F_{i} * \prod_{i=1}^{n} R_{j}(\mathbf{E} . \mathbf{1})
$$

\section{Resultados y discusión}

Se hace una descripción de los mapas temáticos creados, tanto factores como restricciones y las implicaciones de cada criterio. Posteriormente, se muestra la imagen resultante del MCDA y la clasificación en cuatro categorías por su idoneidad para el desarrollo urbano a futuro.

\subsection{Factores $(F)$ y restricciones $(R)$}

\subsubsection{Tenencia de la tierra}

Los resultados obtenidos del mapa de tenencia de la tierra muestran que las zonas federales, la propiedad comunal ejidal y la propiedad parcelaria ejidal abarcan tres cuartas partes del municipio. En cambio, los asentamientos del ejido y la propiedad privada cubren una décima parte de este (Cuadro 3).

Cuadro 3. Tenencia de la tierra del municipio de Acapulco de Juárez

Table 3 Land tenure in the municipality of Acapulco de Juárez

\begin{tabular}{lcc}
\hline \multicolumn{1}{c}{ Régimen de propiedad } & Área $\left(\mathbf{k m}^{2}\right)$ & $\%$ \\
\hline Privada AGEB & 154.0 & 9.1 \\
Asentamientos del ejido & 18.8 & 1.0 \\
Parcelas de ejido & 486.1 & 28.1 \\
Comunal del ejido & 450.8 & 26.0 \\
Zona Federal & 552.5 & 31.9 \\
Cuerpos de Agua & 68.0 & 3.9 \\
\hline
\end{tabular}

De las zonas federales, el polígono más extenso se encuentra al centro-este del municipio y es importante su valor ecológico porque aparentemente no hay intervención humana y ahí se ubica una parte del río Papagayo (Figura 3a).

En el ejido, la propiedad comunal y parcelaria tiene un potencial agrícola importante por las condiciones climáticas con las que cuenta (Botello et al., 2015; WorldClim, 2018). La conservación de estas áreas para el aumento de producción agrícola puede servir para disminuir la dependencia económica del sector turístico. De igual modo, hay parcelas próximas a las zonas urbanas que pueden ser importantes por su fácil acceso a la ciudad.

\begin{tabular}{|c|c|c|}
\hline 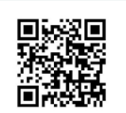 & (c) () (9) & 100 \\
\hline
\end{tabular}




\section{Revista de CIENCIAS AMBIENTALES Tropical Journal of Environmental Sciences}

Revista de Ciencias Ambientales (Trop J Environ Sci) e-ISSN: 2215-3896

(Julio-Diciembre, 2021) . Vol 55(2): 91-110 DOI: https://doi.org/10.15359/rca.55-2.5 Open Access: www.revistas.una.ac.cr/ambientales e-mail: revista.ambientales@una.ac.cr Guerrero-Morales J., Sampedro-Rosas L., Ruz-Vargas M., Silva-Gómez S., Carlos Fonseca C. y Gómez-Albores M.

La propiedad privada se encuentra próxima a la línea litoral y su expansión por la demanda de infraestructura para el turismo a zonas de inundación es latente. Para este caso es necesario frenar la expansión urbana en esa zona por cuestiones de riesgo y de impactos al ecosistema como lo menciona Rodríguez (2017).

\subsubsection{Mapa del potencial de recarga de agua subterránea (PGR) 2017}

La zona donde se identifica mayor recarga al acuífero por infiltración es en la parte norte del municipio (Figura 3b) donde se encuentra mayor precipitación (WorldClim, 2018). También, hay una gran permeabilidad en el centro del municipio por el tipo de suelo (INEGI, 2020). Las zonas al sur, posterior a la línea litoral con baja recarga de agua subterránea son debido al uso de suelo urbano y a que la precipitación es menor que en el norte del municipio. Es importante resaltar que son escasos los estudios de estimación de recarga de agua subterránea con técnicas de sensores remoto sobre el municipio.

\subsubsection{Mapa del promedio de índices de vegetación 1986-2017}

El promedio de índices de vegetación expresa la presencia de biomasa a lo largo de 30 años en todo el municipio. Este indicador ambiental es adecuado para el presente estudio ya que Acapulco es extenso y tiene zonas forestales, agrícolas y zonas urbanas. Existen metodologías para el mismo fin a partir de mediciones directas que resultan relativamente costosas. Las capas raster a nivel global y la estimación de carbono por factores de conversión por tipo de ecosistema para valorar la biomasa (Huete et al. 2015) darían valoraciones espaciales imprecisas debido a que son enfocados a escalas globales o regionales.

Las áreas donde se identifica mayor presencia de actividad fotosintética por la clorofila son en el centro y norte del municipio. En la (Figura 3c) se registra actividad fotosintética tanto de zonas agrícolas como de ecosistemas naturales y es posible relacionar los menores valores del promedio de índices de vegetación con vegetación enferma, suelo desnudo o erosionado.

\subsubsection{Mapa de pendientes de terreno}

Tiwari et al. (2018) menciona que áreas con inclinación homogénea presentan mayor estabilidad en las construcciones. Una de las características del municipio es la fragmentación de la superficie por cambios abruptos de pendientes. Esto se observa en la (Figura 3d).

Las pendientes más pronunciadas se encuentran en el norte de municipio en color rojo en la (Figura 3d). Algunas áreas alrededor de Laguna de Tres Palos se observan en color rojo en la (Figura 3d) debido a que tienen pendiente de terreno menor al $2 \%$ y son susceptibles de inundación. Algunos autores (Tiwari et al., 2018) no toman en cuenta pendientes de terreno menores al $2 \%$ debido a que las zonas de estudio no tienen riesgo de inundación.

\begin{tabular}{|c|c|c|c|c|}
\hline 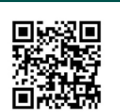 & (c) (i) $\$(0)$ & $\Theta_{\text {AMBENTIIES }}$ & $\frac{1 \%}{2 \%}$ & 101 \\
\hline
\end{tabular}




\section{Revista de CIENCIAS AMBIENTALES Tropical Journal of Environmental Sciences}

Revista de Ciencias Ambientales (Trop J Environ Sci) e-ISSN: 2215-3896

(Julio-Diciembre, 2021) . Vol 55(2): 91-110 DOI: https://doi.org/10.15359/rca.55-2.5 Open Access: www.revistas.una.ac.cr/ambientales e-mail: revista.ambientales@una.ac.cr Guerrero-Morales J., Sampedro-Rosas L., Ruz-Vargas M., Silva-Gómez S., Carlos Fonseca C. y Gómez-Albores M.

De la (Figura 3) es posible observar la heterogeneidad de cada factor en todo el municipio. De la (Figura 3b, c y d) se observa convergencia de alta infiltración, altos valores del promedio del índice de vegetación y pendientes muy inclinadas en el norte del municipio.
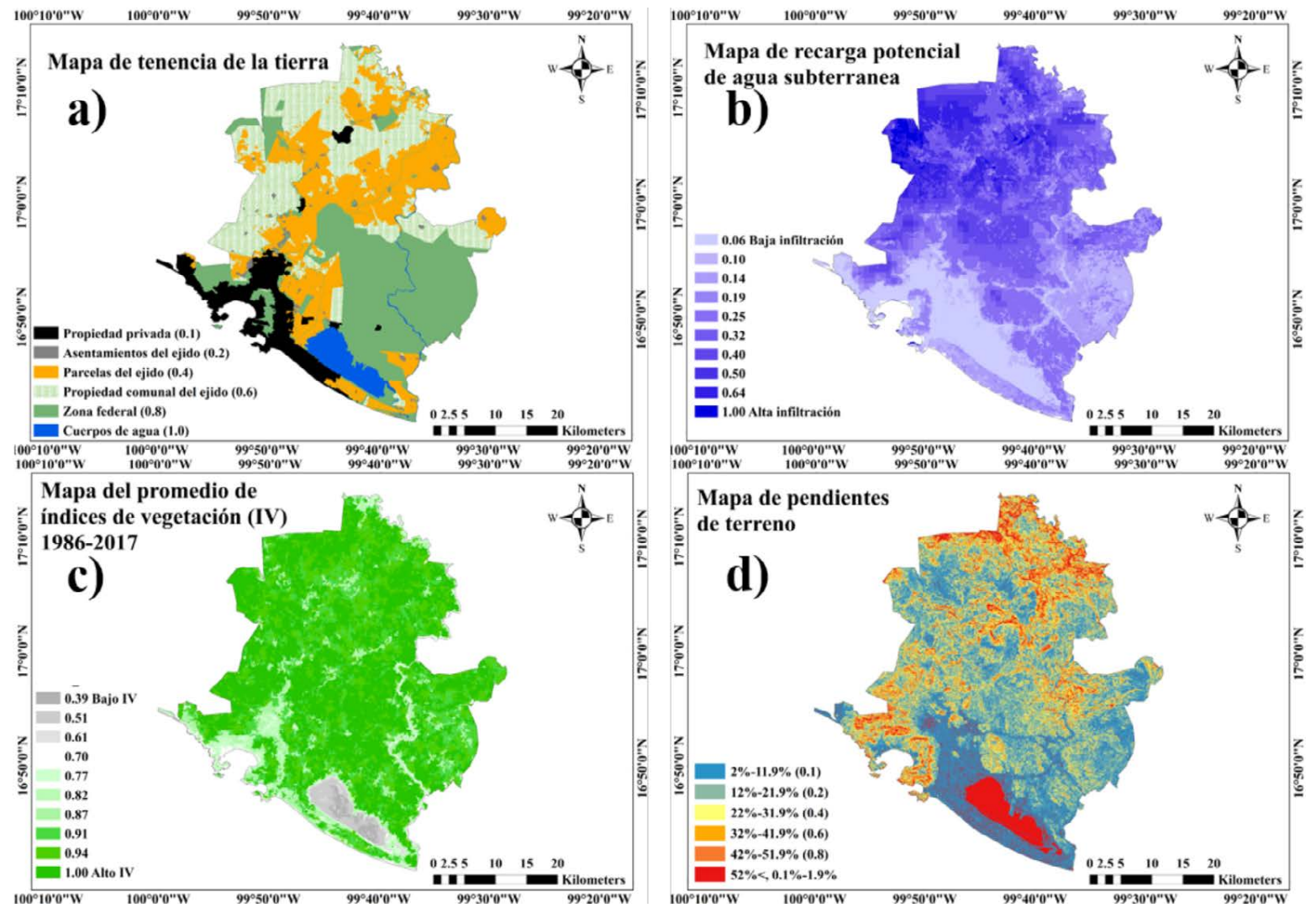

Figura 3. a) Mapa de tenencia de la tierra, b) mapa de PGR, c) mapa del promedio de índices de vegetación de 1986- 2017, d) mapa de pendientes de terreno.

Figure 3. a) Map of land tenure, b) PGR map, c) Map of the average vegetation index from 1986-2017, d) Map of land slopes.

\subsubsection{Mapa de zonas de inundación de registros oficiales}

En la (Figura 4a) se observa que las zonas de peligro de inundación se identifican próximas a la línea litoral y al río Papagayo desde 2003. Al sobreponer la (Figura 4a y 4c) es posible identifica zonas urbanas que se encuentran en riesgo de inundación.

\subsubsection{Mapa de peligro de inundación por aumento del nivel del mar}

El quinto informe de evaluación (AR5) del IPCC reporta dos aspectos que no pueden pasar por alto para el mediano y largo plazo para el municipio de Acapulco, uno es el incremento en

\begin{tabular}{|c|c|c|}
\hline 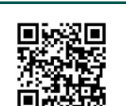 & (c) (i) (5) (0) & 102 \\
\hline
\end{tabular}




\section{Revista de CIENCIAS AMBIENTALES Tropical Journal of Environmental Sciences}

Revista de Ciencias Ambientales (Trop J Environ Sci) e-ISSN: 2215-3896

(Julio-Diciembre, 2021) . Vol 55(2): 91-110 DOI: https://doi.org/10.15359/rca.55-2.5

Open Access: www.revistas.una.ac.cr/ambientales e-mail: revista.ambientales@una.ac.cr Guerrero-Morales J., Sampedro-Rosas L., Ruz-Vargas M., Silva-Gómez S., Carlos Fonseca C. y Gómez-Albores M.

la intensidad de lluvias en zonas de latitudes medias, y el segundo, el incremento del nivel del mar (IPCC, 2014). Al respecto el IPCC sugiere, dentro de las medidas de adaptación al CC la planeación del uso de suelo para gestionar el riesgo.

$\mathrm{Al}$ respecto, en la (Figura $\mathbf{4 b}$ ) se observa las áreas de peligro de inundación en color rojo. Estas áreas convergen con la última planeación urbana más importante, la Zona Diamante (Torres, 2016). Esta zona se ubica al oeste en colindancia con la Bahía de Puerto Marqués, al norte con la Lagua de Tres Palos, al sur con el Océano Pacífico y al este con el Río Papagayo.

\subsubsection{Restricciones de zonas urbanas existentes y cuerpos de agua}

Las zonas urbanas identificadas hasta 2017 fueron de $152.7 \mathrm{~km}^{2}$, el $8.8 \%$ del municipio. Los asentamientos consolidados se encuentran próximos a la línea litoral y al río La Sabana, (Figura 4c).

Los cuerpos de agua considerados como restricción son la Laguna de Tres Palos, el río Papagayo y el río La Sabana. La hidrología superficial y las zonas de amortiguamiento abarcan 80 $\mathrm{km}^{2}$ del municipio, (Figura 4d).
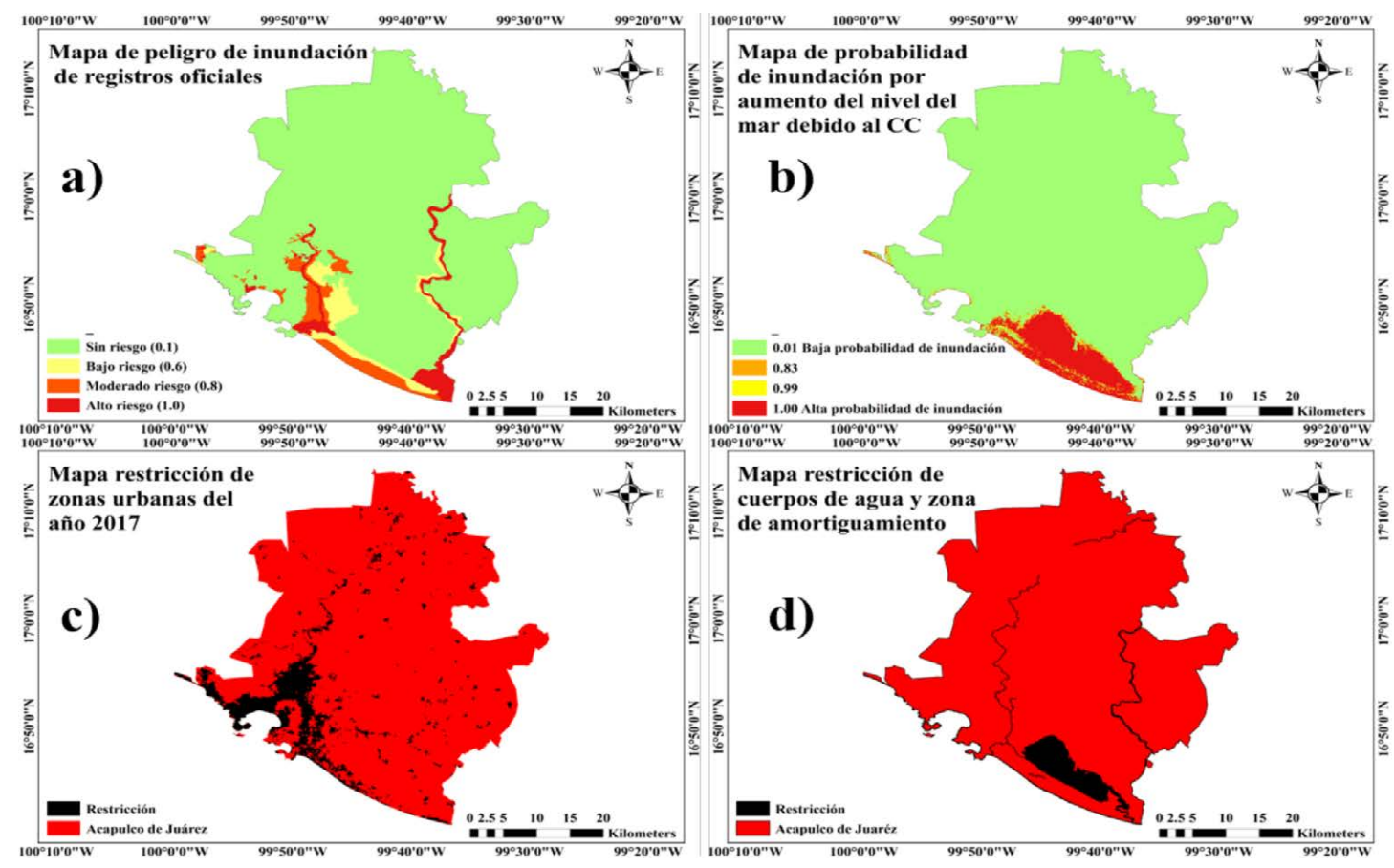

Figura 4. a) Mapa de zonas de inundación de registros oficiales, b) mapa de inundación por aumento del nivel del mar debido al cambio climático, c) mapa de restricción de zonas urbanas actuales (año 2017), d) mapa de restricción de cuerpos de agua y zonas de amortiguamiento.

Figure 4. a) Map of flood zones from official records, b) Map of flooding due to sea level rise due to climate change, c) Map of restriction of current urban areas (year 2017), d) Map of restriction of bodies of water and buffer zones.

\begin{tabular}{|c|c|c|c|c|c|}
\hline 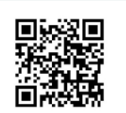 & (c) $\underset{\mathrm{BY}}{(\mathrm{NC}} \mathrm{S}$ & $\underbrace{}_{\text {AMBIFNAIIES }}$ & $\frac{1 \% \%}{20}$ & $\frac{\text { UNA }}{\frac{\text { UNIVERIDAD }}{\text { NACIONAL }}}$ & 103 \\
\hline
\end{tabular}




\section{Revista de CIENCIAS AMBIENTALES Tropical Journal of Environmental Sciences}

Revista de Ciencias Ambientales (Trop J Environ Sci) e-ISSN: 2215-3896

(Julio-Diciembre, 2021) . Vol 55(2): 91-110 DOI: https://doi.org/10.15359/rca.55-2.5

Open Access: www.revistas.una.ac.cr/ambientales e-mail: revista.ambientales@una.ac.cr Guerrero-Morales J., Sampedro-Rosas L., Ruz-Vargas M. Silva-Gómez S., Carlos Fonseca C. y Gómez-Albores M.

\subsection{Análisis de evaluación multicriterio}

El municipio de Acapulco de Juárez presenta distintos factores que benefician o dificultan el desarrollo urbano a futuro, además es notoria la heterogeneidad de los mapas temáticos antes mencionados.

El MCDA hace posible una planeación urbana integrando el peligro de inundación, orografía accidentada, servicios ecosistémicos de soporte y la tenencia de la tierra. Los resultados del MCDA son la composición de seis factores y dos restricciones. El área del municipio es de 1 $726.7 \mathrm{~km}^{2}$. Al eliminar las restricciones (áreas urbanas actuales, cuerpos de agua y buffers) quedan $1509.8 \mathrm{~km}^{2}$ con idoneidad muy alta, media, baja, y muy baja para el crecimiento urbano.

En el (Cuadro 4) se puede observar que el área muy apta para el desarrollo urbano es de $367.03 \mathrm{~km}^{2}$ y es la cantidad suficiente para el desarrollo urbano a futuro debido a que duplica la superficie urbana actual ( $8.8 \%$ en 2017). La superficie del área muy apta representa baja infiltración, poca continuidad de actividad fotosintética, no presenta peligro de inundación y cuenta con pendientes de terreno media y baja.

Cuadro 4. Áreas idóneas para el desarrollo urbano en Acapulco de Juárez

Table 4. Suitable areas for urban development in Acapulco de Juárez

\begin{tabular}{|c|c|c|}
\hline Nivel de idoneidad & $\mathrm{Km}^{2}$ & $\%$ \\
\hline Alta & 367.031 & 24 \\
\hline Moderada & 404.608 & 27 \\
\hline Baja & 355.600 & 24 \\
\hline Muy baja & 374.104 & 25 \\
\hline
\end{tabular}

Las zonas con muy alta aptitud, se indican en color verde en la (Figura 5). Estas zonas permiten la planeación territorial a lo largo y ancho del territorio mitigando los efectos negativos que tiene la urbanización sobre los ecosistemas.

Para suministrar de infraestructura al turismo o sector terciario se encuentran áreas con muy alta aptitud cercanas a la línea litoral. De igual modo, en la Figura 5 se observan distintas zonas en color verde, cercanas a las zonas urbanas actuales para suministrar de vivienda a los habitantes en un futuro. Es importante resaltar que las zonas moderadamente aptas y bajas pueden ser consideradas para desarrollo económico basado en el sector primario.

Las zonas de muy baja aptitud para el desarrollo urbano (color rojo en la) (Figura 5) representan un peligro ecológico y riesgo para la población por fenómenos hidrometeorológicos. (Sarmiento et al. 2020) menciona que la falta de dotación de vivienda en combinación con la exposición a riesgos naturales genera poblaciones vulnerables en todo el mundo. La presente investigación da respuesta a estos temas.

La principal variable que fragmenta y no permite la continuidad de áreas es la pendiente del terreno, es decir, orografía accidentada del municipio.

\begin{tabular}{|c|c|c|c|c|}
\hline 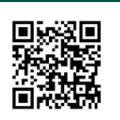 & (c) (i) (\$) & $\overbrace{\text { AMBEFNTALS }}$ & $\frac{1 \%}{\frac{\%}{2}}$ & 104 \\
\hline
\end{tabular}




\section{Revista de CIENCIAS AMBIENTALES Tropical Journal of Environmental Sciences}

Revista de Ciencias Ambientales (Trop J Environ Sci) e-ISSN: 2215-3896

(Julio-Diciembre, 2021) . Vol 55(2): 91-110 DOI: https://doi.org/10.15359/rca.55-2.5 Open Access: www.revistas.una.ac.cr/ambientales e-mail: revista.ambientales@una.ac.cr Guerrero-Morales J., Sampedro-Rosas L., Ruz-Vargas M., Silva-Gómez S., Carlos Fonseca C. y Gómez-Albores M.

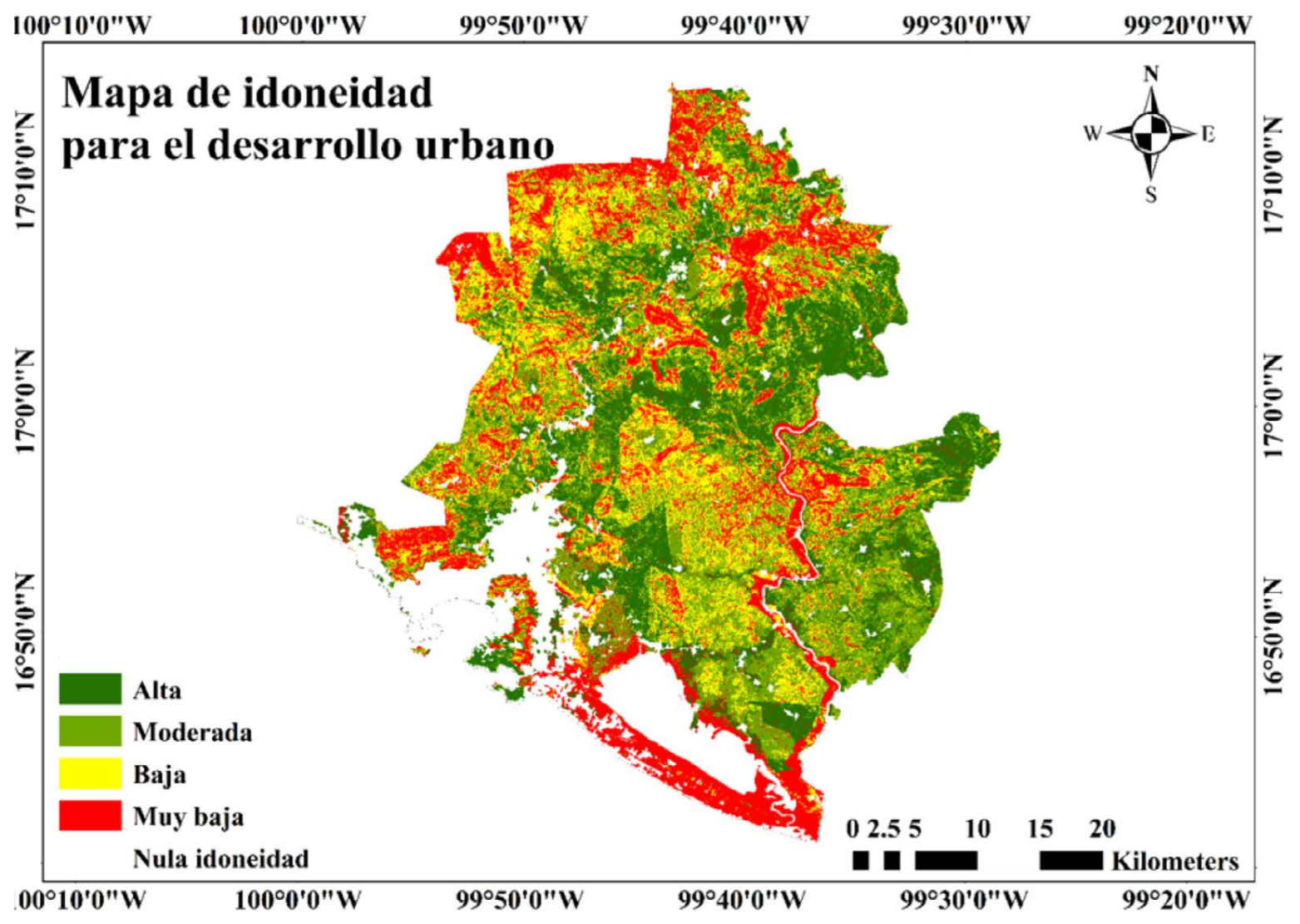

Figura 5. Mapa de idoneidad para el desarrollo urbano en Acapulco de Juárez. Figure 5. Map of suitability for urban development in Acapulco de Juárez.

Al estar integradas las zonas de inundación por aumento del nivel del mar debido al CC y los servicios ecosistémicos en el MCDA la presente investigación es una medida de mitigación y adaptación al CC, recomendada por el IPCC.

\section{Conclusiones}

Uno de los aspectos más relevantes de la presente investigación es que expresa la confrontación entre el riego de inundación y las necesidades de infraestructura turística por vividas distintas regiones costeras e intensificadas con el cambio climático. Los desastres naturales impactan en mayor medida a la población con escasos recursos, por tal motivo, Acapulco es un referente donde interactúan el turismo y la pobreza.

Involucrar factores de distinta naturaleza, representa una forma conciliadora entre los requerimientos urbanos para vivienda y las condiciones ecológicas de preservación, como la tenencia de la tierra, la fisiografía, servicios ecosistémicos y adaptación al CC. Tras proponer una

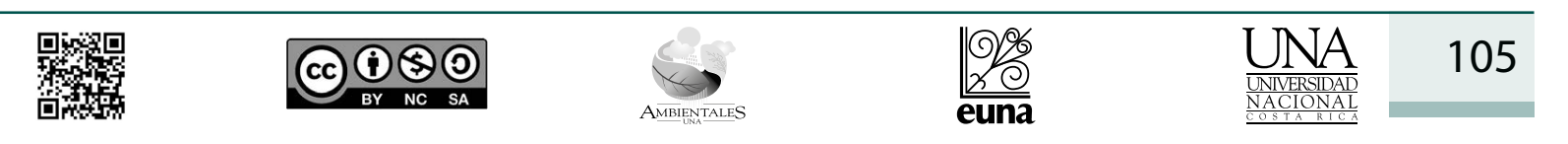




\section{Revista de CIENCIAS AMBIENTALES Tropical Journal of Environmental Sciences}

Revista de Ciencias Ambientales (Trop J Environ Sci) e-ISSN: 2215-3896

(Julio-Diciembre, 2021) . Vol 55(2): 91-110 DOI: https://doi.org/10.15359/rca.55-2.5

Open Access: www.revistas.una.ac.cr/ambientales e-mail: revista.ambientales@una.ac.cr Guerrero-Morales J., Sampedro-Rosas L., Ruz-Vargas M. Silva-Gómez S., Carlos Fonseca C. y Gómez-Albores M.

perspectiva metodológica que abarca la unificación de variables propuestas por Riccioli et al., 2016; Llamas-Torres et al., 2019; Tiwari et al., 2018 y Seghezzo et al. (2017), esta conciliación espacial es lo más sobresaliente del presente estudio,

La presente metodología puede funcionar para armonizar el ordenamiento urbano, ecológico y las zonas ejidales. Es decir, las variantes legislativas de distintas regiones de Latinoamérica pueden ser integradas en un análisis multicriterio espacial que proporcione las mejores zonas para dotar de vivienda a la población en regiones turísticas. Ejemplo de ello es México, donde una de las dificultades a las que se enfrentan es la poca claridad en la vinculación de las atribuciones del municipio (artículo 115) y la asamblea ejidal (Ley Agraria) en el cambio de uso de suelo. Si bien, la presente investigación no resuelve las complicaciones jurídicas, contribuye a identificar zonas a futuro que deben ser gestionadas por gobiernos locales sobre la propiedad privada, la propiedad federal o la propiedad comunal con fundamentos ecológicos y de riesgo, dejando de lado las visiones economicistas de desarrollo.

En esta metodología está expresado el ciclo hidrológico que es un SE de soporte con la recarga potencial de agua subterránea (RPAS), los cuerpos de agua y los buffers o zonas de amortiguamiento a cuerpos de agua. Al considerar estos criterios espaciales se está preservando agua subterránea a las generaciones futuras. El mapa de la RPAS es claramente un indicador hidrológico, al expresar la infiltración subterránea, en concordancia espacial con la precipitación y la temperatura de la zona.

El promedio de los índices de vegetación abarca un tiempo relativamente amplio, 30 años, esto expresa la alta o baja permanencia de biomasa viva. La vegetación, a su vez, protege el suelo y es la base de las cadenas tróficas en ecosistemas terrestres. Estas características hacen de este mapa un indicador ambiental adecuado en relación con el ciclo de carbono. Además, en torno a las zonas urbanas, disminuyen el fenómeno de las islas de calor.

Esta planeación territorial tiene un doble propósito en relación con el CC, ya que es una medida de mitigación y adaptación, debido a que busca afectar, en menor medida, el ciclo de carbono por cambio de uso de suelo (disminución de emisiones) y delimita zonas que serán inundadas por el aumento del nivel del mar generado por el calentamiento global. Este doble propicito es un hallazgo de investigación sobresaliente para regiones afectadas por el fenómeno del Niño en América Latina y el Caribe.

El MCDA resulta adecuado debido a que se tiene un problema complejo con múltiples factores y de distinta naturaleza para una sola respuesta, a futuro, área idónea para el crecimiento urbano en regiones costeras.

Con la identificación de zonas idóneas para el crecimiento urbano delimitadas en este trabajo, no se pone en riesgo vidas humanas y se preserva el ecosistema. Además, se sugiere la diversificación de la economía evidenciando que hay condiciones ambientales (clima) y sociales (extensión ejidal comunal) para la inversión en el sector primario. Estas condiciones como pueden presentarse en regiones turísticas cercanas al ecuador en Latinoamérica, que se sostienen principalmente por el sector terciario.

\begin{tabular}{|c|c|c|}
\hline 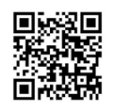 & (c) & 106 \\
\hline
\end{tabular}




\section{Revista de CIENCIAS AMBIENTALES Tropical Journal of Environmental Sciences}

Revista de Ciencias Ambientales (Trop J Environ Sci) e-ISSN: 2215-3896

(Julio-Diciembre, 2021) . Vol 55(2): 91-110 DOI: https://doi.org/10.15359/rca.55-2.5

Open Access: www.revistas.una.ac.cr/ambientales e-mail: revista.ambientales@una.ac.cr Guerrero-Morales J., Sampedro-Rosas L., Ruz-Vargas M. Silva-Gómez S., Carlos Fonseca C. y Gómez-Albores M.

No se calcularon distancias euclidianas como generalmente se consideran para expresar proximidad a vías de comunicación debido a que las carreteras están en función del desarrollo turístico en América Latina.

Al operacionalizar la tenencia de la tierra se apuesta por una cohesión social de producción comunitaria antes que un sector terciario (turismo) que se distingue por su enfoque economicista. De esta forma, se está considerando un distintivo de la región: la agricultura de subsistencia, aspecto que es recurrente en Latinoamérica.

Este proyecto de planeación territorial sienta las bases para una etapa posterior que incluya participación ciudadana y desarrollo regional para aumentar las condiciones de bienestar, principalmente para los habitantes y posteriormente para los turistas, en países vulnerables al cambio climático.

\section{6. Ética y conflicto de intereses}

Las personas autoras declaran que han cumplido totalmente con todos los requisitos éticos y legales pertinentes, tanto durante el estudio como en la producción del manuscrito; que no hay conflictos de intereses de ningún tipo; que todas las fuentes financieras se mencionan completa y claramente en la sección de agradecimientos; y que están totalmente de acuerdo con la versión final editada del artículo."

\section{Agradecimientos}

Las personas autoras agradecen el apoyo recibido del Consejo Nacional de Ciencia y Tecnología (CONACYT) de México por el apoyo financiero. A la revista y su equipo editorial, así como a las personas revisoras, por sus aportes para mejorar la versión final del artículo.

\section{Referencias}

Ayuntamiento Constitucional de Acapulco de Juárez. (2018). Plan Municipal de Desarrollo 20182021. https://acapulco.gob.mx/transparencia/plan-municipal-de-desarrollo-2018-2021/

Botello F., Sánchez-Cordero V., Ortega-Huerta M. A. (2015). Disponibilidad de hábitats adecuados para especies de mamíferos a escalas regional (estado de Guerrero) y nacional (México). Revista Mexicana de Biodiversidad, 86, 226-237. https://doi.org/10.7550/rmb.43353

Comisión Nacional de Áreas Naturales Protegida de México. (2018). Información espacial. http://sig.conanp.gob.mx/website/pagsig/info_shape.htm

Consejo Nacional de Población de México. (2010). Datos Abiertos del Índice de Marginación. http://www.conapo.gob.mx/es/CONAPO/Datos_Abiertos_del_Indice_de_Marginacion

Eastman, R. (2016). TerrSet. Geoespacial monitoring and modeling system. Clark Labs.https:// clarklabs.org/wp-content/uploads/2016/10/Terrset-Manual.pdf

\begin{tabular}{|c|c|c|c|c|c|}
\hline 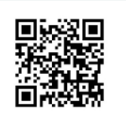 & (c) () (9) & $\overbrace{\text { AMBENTALS }}^{\infty}$ & $\frac{O \%}{2)}$ & $\frac{\text { UNA }}{\frac{\text { UNILERIDAD }}{\text { NACIONAL }}}$ & 107 \\
\hline
\end{tabular}




\section{Revista de CIENCIAS AMBIENTALES Tropical Journal of Environmental Sciences}

Revista de Ciencias Ambientales (Trop J Environ Sci) e-ISSN: 2215-3896

(Julio-Diciembre, 2021) . Vol 55(2): 91-110 DOI: https://doi.org/10.15359/rca.55-2.5 Open Access: www.revistas.una.ac.cr/ambientales e-mail: revista.ambientales@una.ac.cr Guerrero-Morales J., Sampedro-Rosas L., Ruz-Vargas M. Silva-Gómez S., Carlos Fonseca C. y Gómez-Albores M.

Fonseca, C. R., Díaz-Delgado, C., Esteller, M. V. y García-Pulido, D. (2017). Geoinformatics tool with an emergy accounting approach for evaluating the sustainability of water systems: Case study of the Lerma river, Mexico. Ecological Engineering, 99, 436-453. http://dx.doi.org/ 10.1016/j.ecoleng.2016.11.034

Hawes E. y Smith M. (2005). Riparian Buffer Zones: Functions and Recommended Widths. Yale School of Forestry and Environmental Studies. http://www.eightmileriver.org/resources/digital_library/appendicies/09c3_Riparian\%20Buffer\%20Science_YALE.pdf

Huete A., Ponce-Campos G., Zhang Y., Restrepo-Coupe N., Ma X., y Moran M. S. (2015). Monitoring Photosynthesis from Space. In Prasad and Thenkabail (Eds.), Land Resources Monitoring, Modeling, and Mapping with Remote Sensing. CRC Press. https://doi.org/10.1201/b19322

Instituto Nacional de Geografía y Estadística (INEGI). (2015). Censos de población y vivienda 1980-2015. http://www.beta.inegi.org.mx/datos/?init=2\&p=cenCon

Instituto Nacional de Geografía y Estadística (INEGI). (2015). Principales resultados de la Encuesta Intercensal 2015, Guerrero, México. https://www.inegi.org.mx/programas/intercensal/2015/default.html\#Tabulados

Instituto Nacional de Geografía y Estadística (INEGI). (2020). Usos de suelo y vegetación serie VI. Marco Geoestadístico Nacional. Instituto Nacional de Estadística y Geografía. México. Conjunto de datos vectoriales Perfiles de suelos. Escala 1:1 000 000. https://www.inegi.org. $\mathrm{mx} /$ temas/usosuelo/default.html\#Descargas https:/www.inegi.org.mx/temas/mg/default. html\#Descargas https://www.inegi.org.mx/temas/edafologia/default.html\#Descargas

IPCC. (2014). Climate Change 2014: Synthesis Report. Contribution of Working Groups I, II and III to the Fifth Assessment Report of the Intergovernmental Panel on Climate Change. IPCC. https://www.ipcc.ch/

Llamas-Torres I., Bello-Pineda J., Castillo-Burguete, M. T., Leyequien-Abarca E. y Calvo-Irabien L. M. C. (2019). Integrating ecological and socioeconomic criteria in a GIS-based multicriteria-multiobjective analysis to develop sustainable harvesting strategies for Mexican oregano Lippia graveolens Kunth, a non-timber forest product. Land Use Policy, 81, 668-679. https:// doi.org/10.1016/j.landusepol.2018.11.038

MEA. (2005). Ecosystems and human well-being: Synthesis. Milennium Ecosystem Assessment. Washignton D. C. Island Press. Estados Unidos de Norteamérica.

PMD. (2019). Plan Municipal de Desarrollo 2018- 2021. Acapulco de Juaréz. https://acapulco. gob.mx/transparencia/plan-municipal-de-desarrollo-2018-2021/

Protección Civil. (2020). Mapa interactivo. https://acapulco.gob.mx/proteccioncivil/mapa_atlasdigital.html.

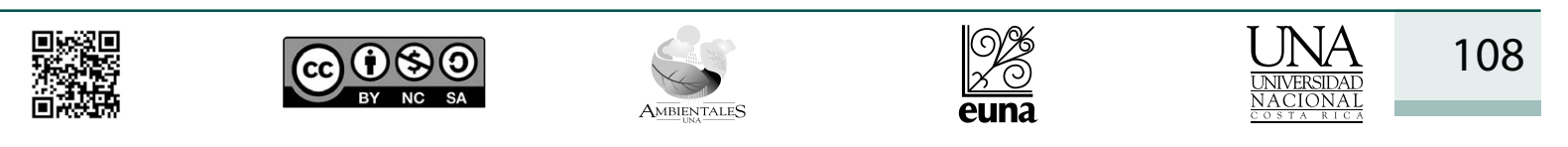




\section{Revista de CIENCIAS AMBIENTALES Tropical Journal of Environmental Sciences}

Revista de Ciencias Ambientales (Trop J Environ Sci) e-ISSN: 2215-3896

(Julio-Diciembre, 2021) . Vol 55(2): 91-110 DOI: https://doi.org/10.15359/rca.55-2.5 Open Access: www.revistas.una.ac.cr/ambientales e-mail: revista.ambientales@una.ac.cr Guerrero-Morales J., Sampedro-Rosas L., Ruz-Vargas M., Silva-Gómez S., Carlos Fonseca C. y Gómez-Albores M.

Registro Agrario Nacional. (2018). Catastro Rural. https://datos.gob.mx/busca/organization/ran

Retama, S.B. Sujitha, D.M. Rivera Rivera, V.C. Shruti, P.F. Rodríguez-Espinosa, M.P. Jonathan. (2019). Evaluation and Management Strategies of Tourist Beaches in the Pacific Coast: A Case Study from Acapulco and Huatulco, Mexico. In Coastal Management Global Challenger and innovations. Academic Press (pp. 79-93). https://doi.org/10.1016/B978-0-12-810473-6.00007-8

Riccioli F., Fratini R., Boncinelli F., El Asmar T., El Asmar J. P., Casini L. (2016). Spatial analysis of selected biodiversity features in protected areas: a case study in Tuscany region. Land Use Policy, 57, 540-554. https://doi.org/10.1016/j.landusepol.2016.06.023

Rodríguez, E. (2017). Los desastres recurrentes en México: El huracán Pauline y la tormenta Manuel en Acapulco, Guerrero. Anuario Electrónico de Estudios en Comunicación Social "Disertaciones", 10(2), 133-152. http://dx.doi.org/10.12804/revistas.urosario.edu.co/ disertaciones/a.4778

Seghezzo, L., Venencia, C., Buliubasich, E., Iribarnegaray, M. y Volante, J. (2017). Participatory, Multi-Criteria Evaluation Methods as a Means to Increase the Legitimacy and Sustainability of Land Use Planning Processes" The Case of the Chaco Region in Salta, Argentina. Environmental Management, 59, 307-324. https://doi.org/10.1007/S00267-016-0779-Y

Sarmiento J. P., Sandoval V. y Jerath M. (2020). The influence of land tenure and dwelling occupancy on disaster risk reduction. The case of eight informal settlements in six Latin American and Caribbean countries. Progress in Disaster Science, 5, 1-8 https://doi.org/10.1016/j. pdisas.2019.100054

Secretaria de Desarrollo Social (SEDESOL). (2004). Acapulco Gro. Atlas de peligros naturales de la ciudad. Identificación y zonificación. https://acapulco.gob.mx/proteccioncivil/documentos/atlas2003.pdf

Tiburcio-Rosales J., Vargas-Pérez E., Terrazas-Domínguez S. Y Aguilar-Sánchez G. (2007). Ordenamiento ecológico territorial utilizando la evaluación multicriterio, para el municipio de San Andrés Chiautla, Estado de México. Revista Chapingo Serie Ciencias Forestales y del Ambiente, 13(2), 91-108. https://www.redalyc.org/articulo.oa?id=62913202

Tiwari A., Tyagi D., Sharma S. K., Suresh M. \& Jain K. (2018). Multi-criteria Decision Analysis for Identifying Potential Sites for Future Urban Development in Haridwar, India. En Kumar A. \& Mozar, S. (Eds.). ICCCE, Springer. (pp. 760-776). https://doi. org/10.1007/978-981-13-0212-1_77

Torres, O. A. (2016). Territorio desigualdad y ciudadanía en Acapulco. En Carrión, F. y Erazo, J. (2016), El derecho a la ciudad en América Latina Visiones desde la política. (pp. 315-332). UNAM https://biblio.flacsoandes.edu.ec/libro.s/144109-opac

\begin{tabular}{|c|c|c|c|c|c|}
\hline 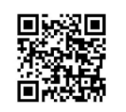 & (c) (1) & $\underset{\text { AMBEINTIIIS }}{S}$ & $\frac{1 \%}{2 \%}$ & 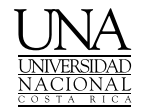 & 109 \\
\hline
\end{tabular}




\section{Revista de CIENCIAS AMBIENTALES Tropical Journal of Environmental Sciences}

Revista de Ciencias Ambientales (Trop J Environ Sci) e-ISSN: 2215-3896

(Julio-Diciembre, 2021) . Vol 55(2): 91-110 DOI: https://doi.org/10.15359/rca.55-2.5 Open Access: www.revistas.una.ac.cr/ambientales e-mail: revista.ambientales@una.ac.cr Guerrero-Morales J., Sampedro-Rosas L., Ruz-Vargas M., Silva-Gómez S., Carlos Fonseca C. y Gómez-Albores M.

UAF [University of Alaska Fairbanks]. (2008). Alaska Satellite Facility. https://www.asf.alaska. edu/sar-data/palsar/terrain-corrected-rtc/

United Nations. (2018). World Urbanization Prospects: The 2018 Revision. https://population. un.org/wup/Publications/Files/WUP2018-Report.pdf.

United States Geological Survey [USGS]. (2019). Science for a changing world. https://glovis. usgs.gov/

Viglizzo E. F., Carreño L. V., Volante J. y Mosciaro M. J. (2011). Valuación de bienes y servicios ecosistémicos: ¿verdad objetiva o cuento de la buena pipa? En: P. Laterra, E. G.,Jobbágy, J. M. Paruelo (Eds.), Valoración de servicios ecosistémicos, conceptos, herramientas y aplicaciones para el ordenamiento territorial. (pp. 17-38). INTA, https://inta.gob.ar/documentos/valoracion-de-servicios-ecosistemicos.-conceptos-herramientas-y-aplicaciones-para-el-ordenamiento-territorial

WorldClim. (2018). WorldClim Global Climate Data Version 2. Feed the Future, The U. S. Government's Hunger \& Food Security Initiative. http://worldclim.org/version2

Zhu J., Zhou Y., Wang S., Wang L., Wang F., Liu W. y Guo B. (2015). Multicriteria decisión analysis for monitoring ecosystem service function of the Three-River Headwaters region of the Qinghai-Tibet Plateau, China. Environmental Monitoring Assessment, 187(355). https://doi. org/10.1007/s10661-015-4523-5

\begin{tabular}{|c|c|c|c|c|}
\hline 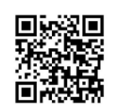 & (c) () & $\underset{\text { AMBENENALIES }}{\infty}$ & $\frac{1 \%}{2 \%}$ & 110 \\
\hline
\end{tabular}

